\title{
Capsule Endoscopy Removal through Flexible Bronchoscopy
}

\author{
Kirk Depriest $^{\mathrm{a}} \quad$ Ali S. Wahla $^{\mathrm{a}}$ Russell Blair ${ }^{\mathrm{a}}$ Bennett Fein ${ }^{\mathrm{b}}$ Robert Chin, Jr. ${ }^{\mathrm{a}}$ \\ a Division of Pulmonary and Critical Care Medicine, Wake Forest University Baptist Medical Center,

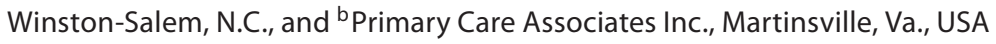

\section{Established Facts}

- Video capsule endoscopy has become an increasingly popular test employed by gastroenterologists worldwide. With the increased use of video capsule endoscopy, pulmonologists are beginning to be consulted on patients who have aspirated the capsule.

\section{Novel Insights}

- With the use of a Roth Net retriever, we were able to remove the capsule with a flexible bronchoscope preventing the need for rigid bronchoscopy in this elderly patient.

\section{Key Words}

Flexible bronchoscopy · Capsule video endoscopy • Aspiration

\begin{abstract}
Since its introduction over 9 years ago, capsule video endoscopy has become increasingly popular within the gastroenterology community, leading to its use in a growing number of patients including the elderly. With the widespread adoption of this diagnostic modality within the elderly population comes the added risk of capsule aspiration. We present such a case where a 90-year-old patient was admitted after
\end{abstract}

accidental aspiration of a capsule. Removal of the capsule posed a therapeutic challenge. In the article, we discuss the novel use of a Roth Net expandable foreign body extractor to remove the capsule using a flexible bronchoscope with minimal need for sedation. As video capsule endoscopy is used more routinely in elderly patients and clinical pulmonologists will be more frequently called up to assist in foreign body removal, our experience highlights that it is possible to remove these large capsules with a flexible bronchoscope and avoid the need for rigid bronchoscopy in this high-risk patient group.

Copyright $\odot 2009$ S. Karger AG, Basel

\section{KARGER \\ Fax +41613061234 E-Mail karger@karger.ch} www.karger.com (c) 2009 S. Karger AG, Basel 0025-7931/10/0795-0421\$26.00/0

Accessible online at: www.karger.com/res
Robert Chin, Jr., MD

Wake Forest University Baptist Medical Center

Winston-Salem, NC 27157 (USA)

Tel. +1 336716 3182, Fax +1 3367167277

E-Mail rchin@wfubmc.edu 


\section{Introduction}

Video capsule endoscopy (VCE) is a disposable $26 \times$ $11 \mathrm{~mm}$ video capsule first introduced in 2000 by Iddan et al. [1]. Since being approved for clinical use, it has become an important tool used in diagnosing small bowl pathologies [2]. We present the case of an elderly patient with multiple comorbidities who presented with capsule aspiration. The capsule was successfully removed with a flexible bronchoscope avoiding the need for rigid bronchoscopy.

\section{Case Report}

A 90-year-old man was referred to our institution for foreign body aspiration. The patient had a history of recurrent melanotic stools and anemia with a $>2$-gram drop in his hemoglobin from $9.4 \mathrm{gm} / \mathrm{dl}$ to $<7 \mathrm{gm} / \mathrm{dl}$. His gastroenterologist performed an endoscopy, colonoscopy and tagged radionucleotide red blood scan; however, the source of bleeding could not be identified. As a result, he ordered a VCE for occult gastrointestinal hemorrhage. The patient's medical problems included coronary artery disease, atrial fibrillation, peripheral vascular disease, cerebrovascular accidents and chronic obstructive pulmonary disease. The patient was being managed for his atrial fibrillation and peripheral vascular disease with warfarin and clopidogrel. These medications were stopped prior to the procedure. After the procedure, he noted some cough, but otherwise, did not complain of dyspnea or chest pain. Initial post-procedure chest X-rays confirmed that the patient had aspirated the capsule into his left mainstem bronchus.

Upon transfer to our institution, the patient was noted to be in no apparent respiratory distress, and oxygen saturation by pulse oximetry was noted to be $95 \%$ via a nasal cannula at $21 / \mathrm{min}$. Therefore, the decision was made to attempt chest percussive therapy (CPT) with postural drainage to potentially aid expectorating the device. Although the patient tolerated the $\mathrm{CPT}$, a follow-up chest X-ray revealed that the capsule had migrated to the right mainstem bronchus. After failure of CPT, the decision was made to attempt bronchoscopic removal. A portable chest X-ray directly prior to the procedure showed that the capsule had migrated back to the left upper lobe bronchus causing atelectasis of the left upper lobe and lingular segments (fig. 1).

\section{Procedure}

We used an Olympus (BF-XT160) therapeutic bronchoscope (working channel $3.2 \mathrm{~mm}$ diameter) via the oral route. On inspection, the capsule was lodged in the left upper lobe (fig. 2). Attempts at removal with a Web $2 \times$ $4 \mathrm{~cm}$ extraction basket (Cook Medical, Ill., USA) were unsuccessful, as was an attempt using a cryoprobe. Subsequently, an expandable basket foreign body retriever



Fig. 1. Capsule (arrow) lodged in the left upper lobe bronchus with associated atelectasis.

(net size $3 \times 6 \mathrm{~cm}$; Roth Net, US Endoscopy, Mentor, Ohio, USA) was employed through the therapeutic bronchoscope working channel. The Roth Net foreign body retriever was originally developed for colonic polyp retrieval but later adapted for foreign body removal. It is a patented butterfly net that forms a stable pouch at one end of a flexible catheter; at the other end, there is a single plunger that allows the net to move in and out of the sheath, simultaneously closing and opening the pouch. The net is deployed flat as it leaves the sheath but can be manipulated to ensnare the foreign body. Initial efforts at removal were unsuccessful; however, the Roth Net was then introduced to the foreign body in the semi-closed position so that it formed a cup in which the capsule could be seated. After manipulation of the net and capsule, the bronchoscope, net and capsule were removed without complication (fig. 3).

The patient was returned to his patient room for further evaluation of the occult bleeding in stable condition and required only $2 \mathrm{mg}$ of midazolam for sedation. The total procedure time (from scope entry to exit) was 36 $\min$. 
Fig. 2. Capsule lodged in the orifice of the left upper lobe bronchus.

Fig. 3. Capsule after successful removal secured within the Roth Net basket.

\section{2}

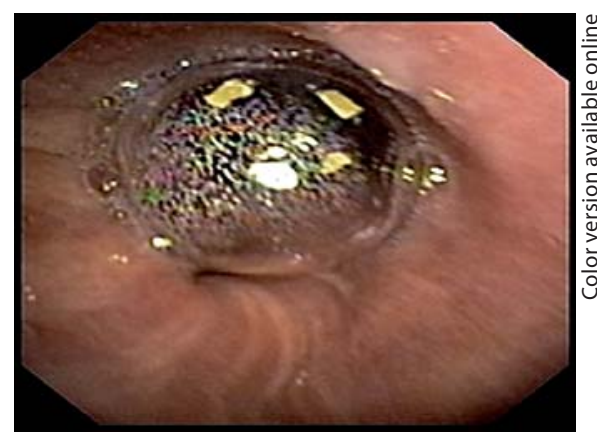

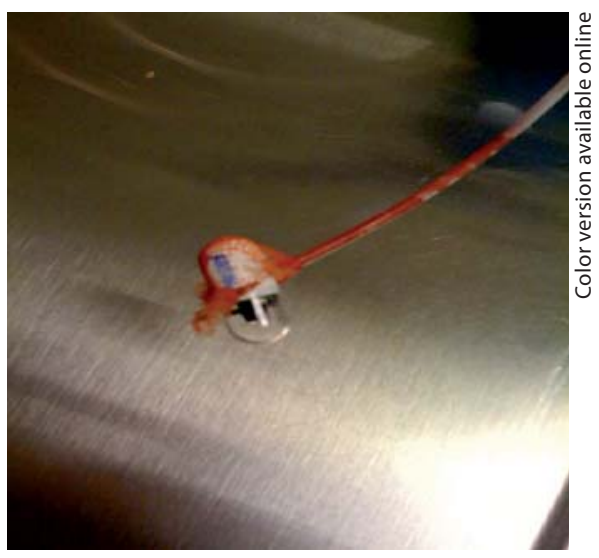

\section{Discussion}

VCE has become an important tool used in diagnosing small bowl pathologies [2]. Since it was introduced into clinical practice, over 80,000 studies have been performed worldwide [3]. The commonest reported complication of capsule endoscopy is capsule retention with a reported frequency of $0.75 \%$ amongst all comers and $8 \%$ amongst known Crohn's disease patients [2]. However, given its size, one can imagine that swallowing it may be problematic in some patients. In a retrospective review of 733 VCEs, Rondonotti et al. [4] reported difficulty or inability to swallow the capsule in $11(1.5 \%)$ patients. In only 1 case did the patient aspirate the capsule; however, he was able to cough it out. We were able to identify 8 case reports of aspiration of VCEs in the gastroenterology and otolaryngology literature [5-12]. All 8 patients described were elderly (age range 64-93 years). This finding is consistent with previous reports of foreign body aspiration in adults which have identified old age as a risk factor for aspiration [13].

Of the 8 reported cases, 4 patients were able to spontaneously cough the capsule out without requiring any intervention. One patient had the capsule lodged in his cricopharyngeus [11] while 2 others required the use of rigid bronchoscopy to remove the capsule $[9,11]$. In 1 case report [7], the use of flexible bronchoscopy for retrieval was mentioned; however, details of the procedure were not described other than that the removal of the capsule 'proved to be rather difficult' because of the smooth surfaces of the capsule. As a consequence of the size of the capsule and the smooth surface, we also encountered some difficulties in removal. However, in our experience, the Roth Net expandable foreign body retriever, when partially closed to form a cup to seat the capsule, proved to be most suited for removal. This device was also successfully used by Sepehr et al. [11] through a rigid bronchoscope.

Most patients who aspirate video capsules are not in respiratory distress, and therefore, an attempt at retrieval with flexible bronchoscopy can be made sparing the elderly patient the risks of general anesthesia and rigid bronchoscopy. The success rate of flexible bronchoscopy in removing foreign bodies has been reported to be $>90 \%$ [14-16]. Therefore, we recommend consideration of removal of foreign bodies with flexible bronchoscopy by an experienced team with the availability of rigid bronchoscopy. It is important to remember that excessive manipulation into the airway when flexible bronchoscopy is unsuccessful can lead to complications that could be avoided by early conversion to rigid bronchoscopy.

References

Respiration 2010;79:421-424
1 Iddan G, Meron G, Glukhovsky A, Swain P: Wireless capsule endoscopy. Nature 2000; 405:417.

2 Eliakim R: Video capsule endoscopy of the small bowel. Curr Opin Gastroenterol 2008; 24:159-163.

-3 Remedios ML, Appleyard M: Capsule endoscopy: current indications and future prospects. Intern Med J 2005;35:234-239.

4 Rondonotti E, Herrerias JM, Pennazio M, Caunedo A, Mascarenhas-Saraiva $M$, de Franchis R: Complications, limitations, and failures of capsule endoscopy: a review of 733 cases. Gastrointest Endosc 2005;62:712-716; quiz 752,754

5 Schneider AR, Hoepffner N, Rösch W, Caspary WF: Aspiration of an M2A capsule. Endoscopy 2003;35:713. 
6 Nathan SR, Biernat L: Aspiration - an important complication of small-bowel video capsule endoscopy. Endoscopy 2007;39 (suppl 1):E343.

7 Buchkremer F, Herrmann T, Stremmel W: Mild respiratory distress after wireless capsule endoscopy. Gut 2004;53:472.

$\checkmark 8$ Shiff AD, Leighton JA, Heigh RI: Pulmonary aspiration of a capsule endoscope. Am J Gastroenterol 2007;102:215-216.

$\checkmark 9$ Tabib S, Fuller C, Daniels J, Lo SK: Aspiration of a capsule endoscope. Gastrointest Endosc 2004;60:845-848.
10 Sinn I, Neef B, Andus T: Aspiration of a capsule endoscope. Gastrointest Endosc 2004; 59:926-927.

-11 Sepehr A, Albers GC, Armstrong WB: Aspiration of a capsule endoscope and description of a unique retrieval technique. Otolaryngol Head Neck Surg 2007;137:965-966.

12 Fleischer DE, Heigh RI, Nguyen CC, Leighton JA, Sharma VK, Musil D: Videocapsule impaction at the cricopharyngeus: a first report of this complication and its successful resolution. Gastrointest Endosc 2003;57: 427-428.
13 Boyd M, Chatterjee A, Chiles C, Chin R Jr: Tracheobronchial foreign body aspiration in adults. South Med J 2009;102:171-174.

14 Surka A, Chin R, Conforti J: Bronchoscopic myths and legends: airway foreign bodies. Clin Pulm Med 2006;3:209-211.

15 Gencer M, Ceylan E, Koksal N: Extraction of pins from the airway with flexible bronchoscopy. Respiration 2007;74:674-679.

16 Tabuena RP, Zuccatosta L, Tubaldi A, Gasparini S: An unusual iatrogenic foreign body (surgical gauze) in the trachea. Respiration 2008;75:105-108. 